\title{
EXISTENCE AND PRECISE ASYMPTOTIC BEHAVIOR OF STRONGLY MONOTONE SOLUTIONS OF SYSTEMS OF NONLINEAR DIFFERENTIAL EQUATIONS
}

\author{
JAROSLAV JAROŠ AND KUSANO TAKAŜI
}

Abstract. We analyze positive solutions of the two-dimensional systems of nonlinear differential equations

$$
\begin{array}{cl}
x^{\prime}+p(t) y^{\alpha}=0, & y^{\prime}+q(t) x^{\beta}=0, \\
x^{\prime}=p(t) y^{\alpha}, & y^{\prime}=q(t) x^{\beta},
\end{array}
$$

in the framework of regular variation and indicate the situation in which system (A) (resp. (B)) possesses strongly decreasing solutions (resp. strongly increasing solutions) with accurate asymptotic behavior as $t \rightarrow \infty$.

Mathematics subject classification (2010): 34C11, 26A12.

Keywords and phrases: systems of differential equations, positive solutions, asymptotic behavior, regularly varying functions.

\section{REFERENCES}

[1] N. H. Bingham, C. M. Goldie and J. L. Teugels, Regular Variation, Encyclopedia of Mathematics and its Applications, 27, Cambridge University Press, Cambridge, 1987.

[2] W. A. Coppel, Stability and Asymptotic Behavior of Differential Equations, D. C. Heath and Company, Boston, 1965.

[3] O. Haupt And G. Aumann, Differential- und Integralrechnung, 2, W. de Gruyter, Berlin, 1938.

[4] J. JAROŠ, T. KUSANO AND T. TANIGAWA, Asymptotic analysis of positive solutions of a class of third order nonlinear differential equations in the framework of regular variation, Math. Nachr., 286 (2013) 205-223.

[5] T. Kusano And J. Manojlović, Precise asymptotic behavior of solutions of the sublinear EmdenFowler differential equation, Appl. Math. Comput., 217 (2011), 4382-4396.

[6] T. Kus ANO AND J. MANOJLOVIĆ, Asymptotic behavior of positive solutions of sublinear differential equations of Emden-Fowler type, Comput. Math. Appl., 62 (2011), 551-565.

[7] V. MARIĆ AND J. MANOJLOVIĆ, An asymptotic analysis of positive solutions of Thomas-Fermi type sublinear differential equations, Mem. Differential Equations Math. Phys., 57 (2012), 76-94.

[8] T. KusAno, V. Marić AND T. TANigaWA, An asymptotic analysis of positive solutions of generalized Thomas-Fermi differential equations - The sub-half-linear case, Nonlinear Anal., 75 (2012), 2474-2485.

[9] V. Marić, Regular Variation and Differetial Equations, Lecture Notes in Mathematics 1726, Springer-Verlag, Berlin, 2000.

[10] J. D. Mirzov, Asymptotic Properties of Solutions of Systems of Nonlinear Nonautonomous Ordinary Differential Equations, Folia Facultatis Scientiarium Naturalium Universitatis Massarykianae Brunensis, Mathematica 14, Masaryk University, Brno, 2004. 